\title{
Get off your butt - and live longer
}

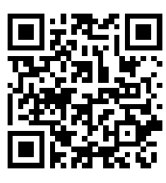

Sedentary habits shorten your life almost as much as smoking (by 1.8 v. 2.5 years) - even if you exercise regularly. ${ }^{[1]}$

These are among the latest research findings presented by internationally-respected University of Cape Town (UCT) kineticist Dr Tracy Kolbe-Alexander, at a health-journalism seminar focussing on non-communicable diseases (NCDs) held at Rhodes University in Grahamstown in August. Kolbe-Alexander was quick to reassure anti-smoking and fitness campaigners that ground-breaking new 'movement' research, addressing what she termed 'a global epidemic of sitting, should not outshine or replace vital exercise, antitobacco or anti-alcohol abuse messages. She emphasised that a holistic approach is essential to mitigate NCDs, which are responsible for half of all deaths worldwide and aggravated by damaging lifestyle behaviours.

In Kolbe-Alexander's field, 'movement, any movement' is the new game in town. 'We have an epidemic of sitting, be it commuting, in the workplace, in the home environment or during leisure time,' she said. The recent South African Youth Risk Behaviour Survey by Reddy et al. ${ }^{[2]}$ showed how vigorous physical activity among local youth has dropped, from $45 \%$ of those surveyed in 2002 to below $43 \%$ in 2008 . Moderate physical activity over the same period subsided even further, from $35 \%$ to $30 \%$. Meanwhile, the percentage of youths who admitted to being 'inactive' grew from $38 \%$ to $43 \%$, and the percentage of those who reported watching more than
3 hours of television per day had jumped from $28 \%$ to $30 \%$.

Kolbe-Alexander said that, worldwide, $31.1 \%$ of adults are estimated to be physically inactive, while more than $80 \%$ of adolescents are not meeting the physical activity recommendations of at least 30 minutes per day of exercise or 150 minutes of exercise per week. Like her harm-reduction colleagues fighting tobacco and alcohol abuse and poor diet, she said framing issues in a stigmatising, blaming manner that focuses solely on the individual's responsibility misses the mark. Over recent decades, environmental opportunities for physical activity have diminished dramatically in areas such as transport, work and home, including the built environment. In stark contrast, opportunities for sitting amounted to a full 15.5 hours of our waking time, from sitting down for meals to sitting at a desk, in a car or in front of the

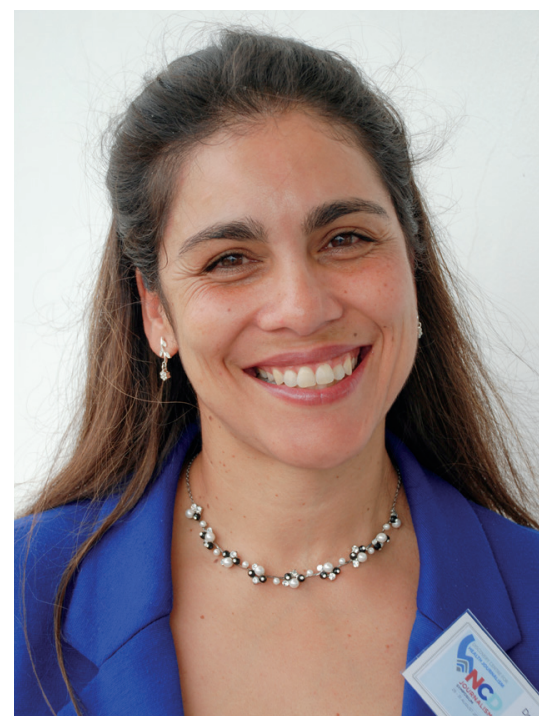

Dr Tracy Kolbe-Alexander, University of Cape Town kineticist.

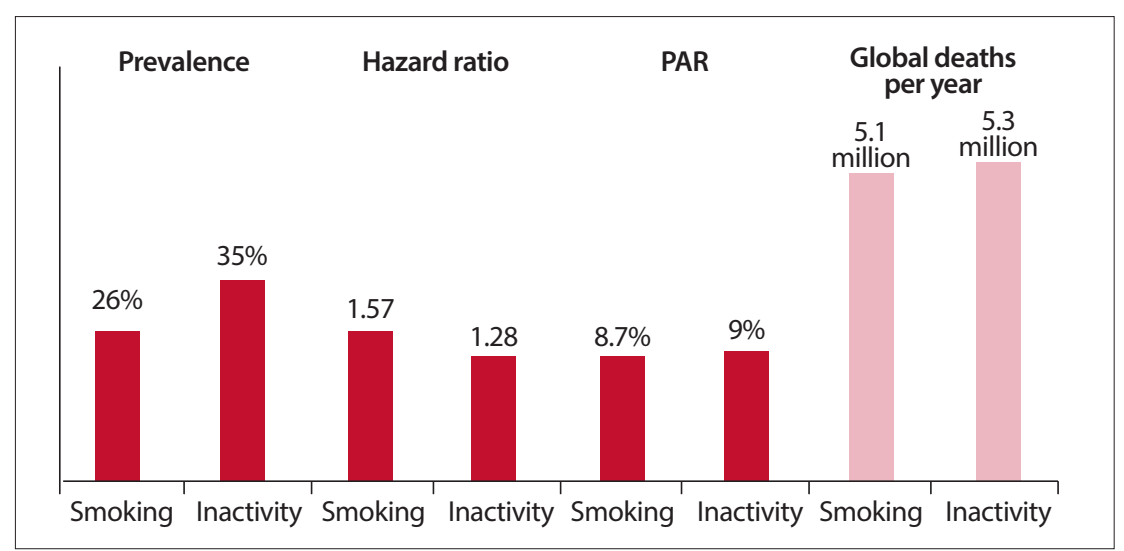

Sedentary behaviour causes more deaths than smoking. $P A R=$ proven acceptable range. 


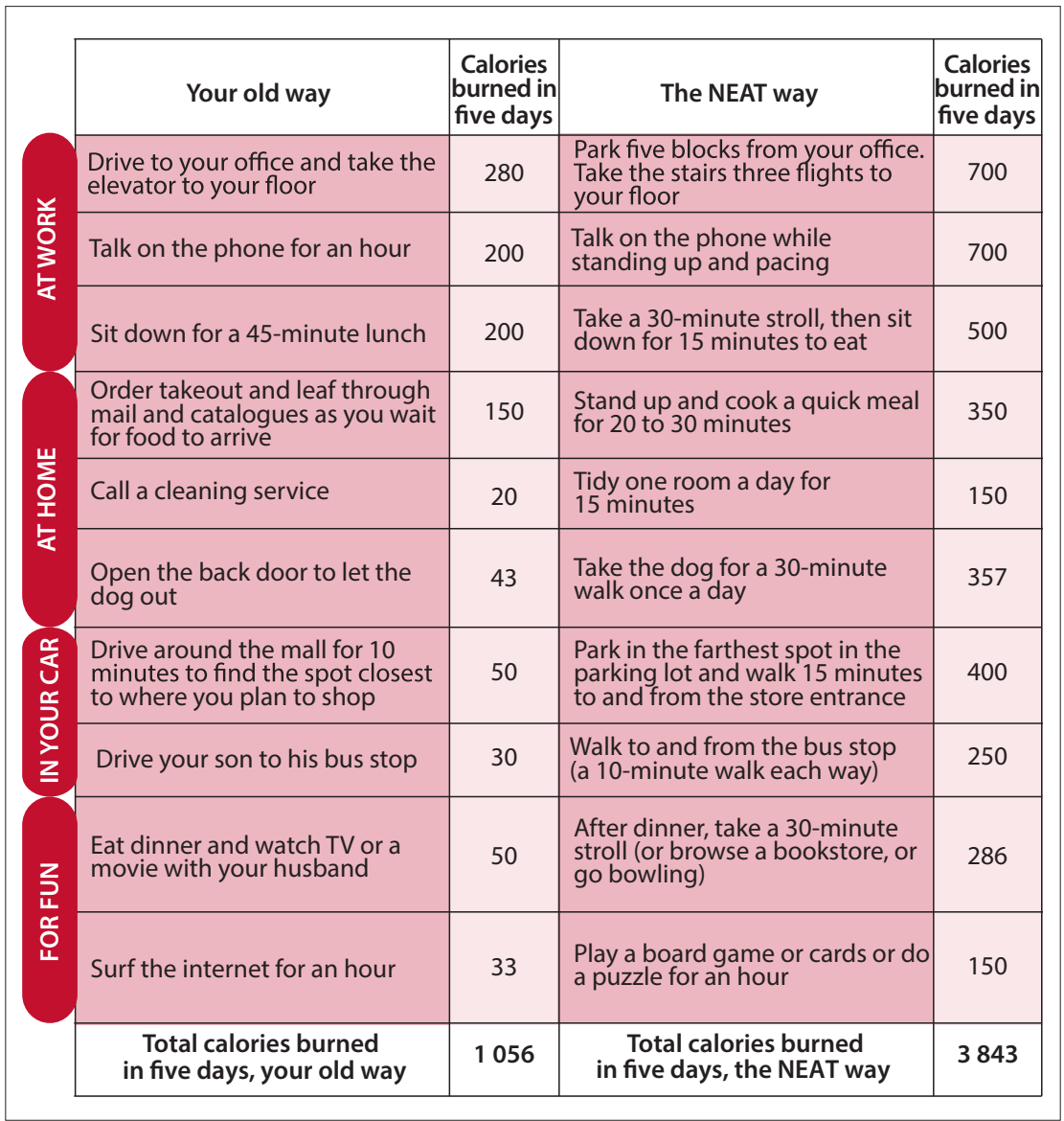

Increasing non-exercise activity thermogenesis (NEAT) and reducing sitting.

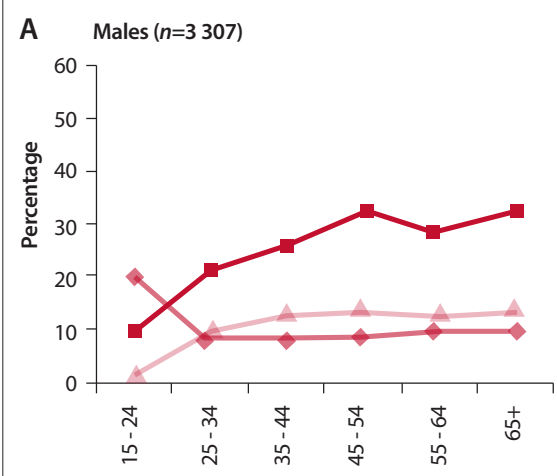

B $\quad$ Males $(n=2572)$
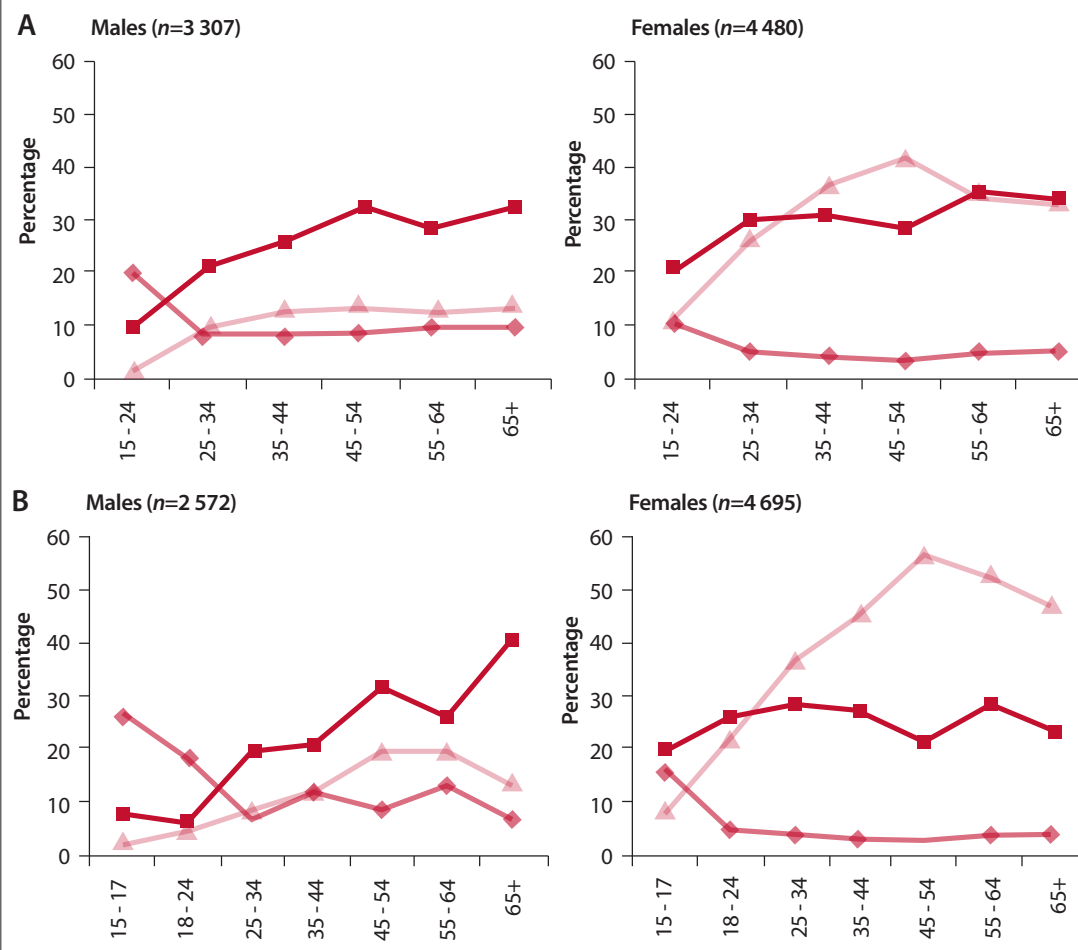

Females $(n=4695)$

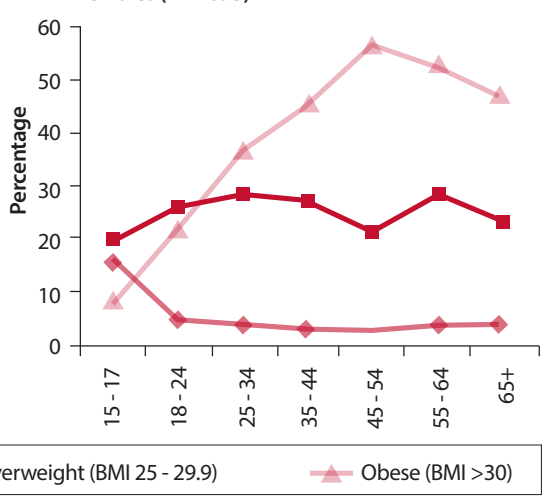

Secular trend for obesity in South Africans over 10 years from (A) 2003 to (B) 2012. (BMI = body mass index in $\mathrm{kg} / \mathrm{m}^{2}$.)
TV. Research also showed that, on average, every single hour of TV viewed after the age of 25 reduces the viewer's life expectancy by 21.8 minutes. ${ }^{[3]}$ Kolbe-Alexander punted 'non-exercise activity thermogenesis' (NEAT) as 'key' in thinking about 'the other 23 and a half hours' (i.e. what happens in the time when you're not doing your daily 30 minutes of cardiovascular exercise).

Varying by 2000 kilocalories (kcal)/day, NEAT ranged from sitting and standing to chewing gum $(15 \mathrm{kcal} / \mathrm{h})$, fidgeting, stair climbing and walking at various speeds. ${ }^{[4]}$ Breaking up sitting time had positive health outcomes - independent of total sitting time - and resulted in improved waist circumference, high-density lipoprotein (HDL) cholesterol levels and c-reactive protein levels. She said 'exciting' new research also shows that sitting is an independent risk factor for all-cause mortality and coronary artery disease mortality. ${ }^{[5]}$

Kolbe-Alexander's 'get moving' message was backed by her colleague, Prof. Vicki Lambert, of the UCT/Medical Research Council Research Unit for Exercise Sports and Sports Medicine and a fellow global consultant. Citing the results of the first-ever South African National Health and Nutrition Examination Survey (SANHANES $\left.{ }^{*}\right),{ }^{[6]}$ Lambert flagged an alarming $15 \%$ increase in obesity (defined as a body mass index (BMI) of $\geq 30 \mathrm{~kg} / \mathrm{m}^{2}$ ) among South African women aged 45 - 54 between 2003 and 2012, bringing its current prevalence up to $56 \%$. She described the differences between men and women that SANHANES revealed as 'astonishing'. SANHANES's snapshot survey of obesity in men aged 45 - 54 last year put prevalence at $18 \%$ compared with women at $56 \%$. However, in the same survey the profile changed for overweight people (defined as having a BMI of $25-29.9 \mathrm{~kg} / \mathrm{m}^{2}$ ), with prevalence among men at $32 \%$ and women at $22 \%$.

Lambert said that the overall prevalence of inactivity made it the biggest single risk factor for death. She praised the National Department of Health for setting 2020 as the target date for reducing obesity and overweight prevalence by $10 \%$ and increasing the prevalence of 150 minutes or more exercise per week among South Africans by the same percentage. Like Kolbe-Alexander, she stressed that when it comes to NCDs, most contributing factors are socially determined and out of the individual's control. For example, early childhood stunting is an independent risk factor for a child to be overweight. One study in Khayelitsha township, Cape Town, showed that early life deprivation (childhood hunger), income, education, body image and a role in household decision-making are strong 
determinants of obesity in adult women, but not in men. ${ }^{[7]}$

'Why don't people have five fruit and veg per day? It may or may not be volitional, so you have to look at lifestyle a little differently, said Lambert. The term 'food desert' has been coined in North America, because of the way people shape their environment by what they can afford and what they like. ${ }^{[3]}$ She gave the example of how supermarkets tailor their produce to high- and low-income customers and cited a study showing how prices of fresh fruit and vegetables had soared between 1979 and 2009, compared with more modest increases in the consumer price index, sugar, sweets and carbonated drinks.

Lambert said a key intervention would be placing healthier foods in the cash-register areas of supermarkets instead of the usual fare of sweets, chocolates and fizzy drinks. The best randomised controlled trial globally has shown that discounting healthy food to the value of VAT improved fruit and vegetable buying among disadvantaged communities. This raises the question of whether choice should be socially engineered or left up to the individual. Lambert pointed to a school feeding scheme in Brazil which brings fresh produce from family farms and co-operatives directly to schools, thus hugely benefitting all parties involved, which she praised as a 'remarkable achievement worth emulating here'. 'If I was in government I'd bring in the Brazilian model,' she added.

Lambert stressed that the youth risk behaviour component of SANHANES was particularly alarming: for the first time in history, the current generation of children is expected to die earlier than their parents. Between 2002 and 2008, obesity rates among South African male adolescents more than doubled, while among their female counterparts they rose from $5 \%$ to $7.5 \% \cdot{ }^{[8]}$

Lambert concluded by quoting Dr Margaret Chan, Director General of the World Health Organization, addressing the 8th Global Conference on Health Promotion in Helsinki this June: 'Not one single country has managed to turn around its obesity epidemic in all age groups. This is not a failure of individual willpower. This is a failure of political will to take on big business.'

*SANHANES was a comprehensive health and nutrition 2012 study that yielded critical information on emerging epidemics of noncommunicable diseases. It also analysed the underlying social, economic, behavioural and environmental factors that drives these diseases in the South African population.

\section{Chris Bateman \\ chrisb@hmpg.co.za}

1. Katzmarzyk PT, Lee IM. Sedentary behavior and life expectancy in the USA: A cause-deleted life table analysis. BMJ Open 2012;2(4):e000828. [http://dx.doi.org/10.1136/ bmjopen-2012-000828

2. Reddy SP, James S, Sewpaul R, et al. Umthente Uhlaba Usamila - The 2nd South African Youth Risk Behaviour Survey 2008. Pretoria: Department of Health, 2010. http:// www.mrc.ac.za/healthpromotion/yrbs_2008_final_report.pdf (accessed 15 October 2013).

3. Veerman IL, Healy GN, Cobiac LJ, et al. Correction: Television viewing time and reduced life expectancy: A life table analysis. $\mathrm{Br}$ J Sports Med 2012:46:1144. [http///dxdoiorg/10.1136/ Br J Sports Med 2012;46:1144. [http://dx.doi.org/10.1136/
bjsm.2011.085662]. bjsm.2011.0856

Levine JA. Nonexercise activity thermogenesis (NEAT): Environment and biology. Am J Physiol Endocrinol Metab 2004; 286:E675-E685. [http://dx.doi.org/10.1152/ajpendo.00562.2003] 5. Katzmarzyk PT, Church T, Craig CL, Bouchard C. Sitting time and mortality from all causes, cardiovascular disease, and cancer. Med Sci Spors Exerc 2009;41(5):998-1005. [http://dx.doi. org/10.1249/MSS.0b013e3181930355].

6. Hoosain E, Dwane N, Reddy P, et al. South African National Health and Nutrition Examination Survey. Pretoria: Human Sciences Research Council, 2013. http://www.hsrc.ac.za/en/ research-outputs/view/6493 (accessed 15 October 2013).

7. Case A, Menendez A. Sex differences in obesity rates in poor countries: Evidence from South Africa. Economics and Human Biology 2009;7(3):271-282.

8. Reddy SP, Resnicow K, James S, et al. Dose-response relationship in overweight and obesity across SES categories. Am J Public Health 2012;102(2):262-268. [http://dx.doi. org/10.2105/AJPH.2011.300222]

S Afr Med J 2013;103(11):821-823.

DOI:10.7196/SAMJ.7564 